University of South Carolina

Scholar Commons

2005

\title{
New standards for reducing gravity data: The North American gravity database
}

\author{
William J. Hinze \\ Purdue University, bima@insightbb.com \\ Carlos Aiken \\ University of Texas at Dallas \\ John Brozena \\ Bernard Coakley \\ University of Alaska Fairbanks \\ David Dater
}

See next page for additional authors

Follow this and additional works at: https://scholarcommons.sc.edu/geol_facpub

Part of the Earth Sciences Commons

\section{Publication Info \\ Published in Geophysics, Volume 70, Issue 4, 2005, pages J25-J32.}

Hinze, W. J., Aiken, C., Brozena, J., Coakley, B., Dater, D., Flanagan, G., Forsberg, R., Hildenbrand, T., Keller, G. R., Kellogg, J., Kucks, R., Li, X., Mainville, A., Morin, R., Pilkington, M., Plouff, D., Ravat, D., Roman, D., Urrutia-Fucugauchi, J., Veronneau, M., Webring, M., \& Winester, D. (2005). New standards for reducing gravity data: The North American gravity database. Geophysics, 70 (4), J25-J32.

(C) Geophysics 2005, Society of Exploration Geophysicists

This Article is brought to you by the Earth, Ocean and Environment, School of the at Scholar Commons. It has been accepted for inclusion in Faculty Publications by an authorized administrator of Scholar Commons. For more information, please contact digres@mailbox.sc.edu. 


\section{Author(s)}

William J. Hinze, Carlos Aiken, John Brozena, Bernard Coakley, David Dater, Guy Flanagan, Rene Forsberg, Thomas Hildenbrand, G. Randy Keller, James N. Kellogg, Robert Kucks, Xiong Li, Andre Mainville, Robert Morin, Mark Pilkington, Donald Plouff, Dhananjay Ravat, Daniel Roman, Jamie Urrutia-Fucugauchi, Marc Veronneau, Michael Webring, and Daniel Winester 


\title{
New standards for reducing gravity data: The North American gravity database
}

\author{
William J. Hinze ${ }^{1}$, Carlos Aiken², John Brozena ${ }^{3}$, Bernard Coakley ${ }^{4}$, David Dater ${ }^{5}$, \\ Guy Flanagan ${ }^{6}$, Rene' Forsberg ${ }^{7}$, Thomas Hildenbrand ${ }^{8}$, G. Randy Keller ${ }^{9}$, James Kellogg ${ }^{10}$, \\ Robert Kucks ${ }^{8}$, Xiong $\mathrm{Li}^{11}$, Andre Mainville ${ }^{12}$, Robert Morin ${ }^{8}$, Mark Pilkington ${ }^{12}$, \\ Donald Plouff ${ }^{8}$, Dhananjay Ravat ${ }^{13}$, Daniel Roman ${ }^{14}$, Jamie Urrutia-Fucugauchi ${ }^{15}$, \\ Marc Véronneau ${ }^{12}$, Michael Webring ${ }^{8}$, and Daniel Winester ${ }^{14}$
}

\begin{abstract}
The North American gravity database as well as databases from Canada, Mexico, and the United States are being revised to improve their coverage, versatility, and accuracy. An important part of this effort is revising procedures for calculating gravity anomalies, taking into account our enhanced computational power, improved terrain databases and datums, and increased interest in more accurately defining long-wavelength anomaly components. Users of the databases may note minor differences between previous and revised database values as a result of these procedures. Generally, the differences do not impact the interpretation of local anomalies but do improve regional anomaly studies. The most striking revision is the use of the internationally accepted terrestrial ellipsoid for
\end{abstract}

the height datum of gravity stations rather than the conventionally used geoid or sea level. Principal facts of gravity observations and anomalies based on both revised and previous procedures together with germane metadata will be available on an interactive Web-based data system as well as from national agencies and data centers. The use of the revised procedures is encouraged for gravity data reduction because of the widespread use of the global positioning system in gravity fieldwork and the need for increased accuracy and precision of anomalies and consistency with North American and national databases. Anomalies based on the revised standards should be preceded by the adjective "ellipsoidal" to differentiate anomalies calculated using heights with respect to the ellipsoid from those based on conventional elevations referenced to the geoid.

\section{INTRODUCTION}

Current processing procedures as described in geophysical textbooks for reducing observed gravity data to anomaly form generally were formalized in the 1920s and 1930s, back when pendulum and portable gravimeters were developed for acquiring large numbers of observations for petroleum exploration (e.g., Hubbert and Melton, 1928). These procedures

\footnotetext{
Manuscript received by the Editor June 17, 2004; revised manuscript received January 6, 2005; published online July 7, 2005. Republished online with author name correction July 15, 2005.

${ }^{1}$ Purdue University, Department of Earth \& Atmospheric Sciences, North American Gravity Database Committee, 30 Brook Hollow Lane, West Lafayette, Indiana 47906. E-mail: bima@insightbb.com.

${ }^{2}$ University of Texas-Dallas, Dallas, Texas.

${ }^{3}$ U.S. Naval Research Laboratory.

${ }^{4}$ University of Alaska.

${ }^{5}$ National Geophysical Data Center, NOAA.

${ }^{6}$ ConocoPhillips.

${ }^{7}$ Danish National Survey \& Cadastre.

${ }^{8}$ U.S. Geological Survey.

${ }^{9}$ University of Texas-El Paso, El Paso, Texas.

${ }^{10}$ University of South Carolina.

${ }^{11}$ Fugro Robertson Inc.

${ }^{12}$ Natural Resources Canada.

${ }^{13}$ University of Southern Illinois-Carbondale.

${ }^{14}$ National Geodetic Survey, NOAA.

${ }^{15}$ Universidad Nacional Autónoma de México.

(C) 2005 Society of Exploration Geophysicists. All rights reserved.
} 
were dictated by the accuracy requirements of the gravity surveys, survey objectives, and limitations in computational power, terrain databases, and absolute-gravity accuracies. Generally, surveys were of a local nature in relatively flat-lying areas, permitting numerous simplifying assumptions in the procedures that minimized the computational requirements.

Despite the simplifying assumptions, these procedures, with minimal modification, continue to be used in local surveys for a variety of exploration- and engineering-related problems that require high accuracy (e.g., Telford et al., 1990), in regions of rugged topography, and in regional anomaly compilations. The first comprehensive Bouguer gravity anomaly map of the United States (Woollard and Joesting, 1964) was based on these procedures, and most stations were uncorrected for terrain. The Society of Exploration Geophysicists' Bouguer gravity anomaly map of the U.S. (Society of Exploration Geophysicists, 1982; Godson, 1985; O'Hara and Lyons, 1985) and the North American Bouguer gravity anomaly map (Committee for the Gravity Anomaly Map of North America, 1987) and their associated databases, which have been widely distributed, used current standard procedures and were corrected only for regional terrain in areas of substantial relief.

As more accurate gravity anomalies have become of interest, especially regional anomaly compilations and observations in rugged topography, modifications to reduction procedures have been investigated (e.g., Olivier and Hinze, 1986; LaFehr, 1991a, b, 1998; Chapin, 1996a; Talwani, 1998; Li and Götze, 2001) and implemented on a limited basis, but they have not been used generally and have not been used to prepare national and North American gravity databases. Use of these modifications has received impetus from the availability of improved terrain and geoid databases, enhanced computational power, and increased use of global positioning system (GPS) technology to establish the location and heights of gravity stations (e.g., Fairhead et al., 2003; Hackney and Featherstone, 2003). As a result, when plans were being made to revise the North American gravity database, the decision was made to upgrade its quality not only by increasing the number and coverage of observations but also to utilize improved procedures to increase the accuracy of anomaly values. Subsequently, the standards for the North American gravity database also were accepted for the databases of Canada, Mexico, and the United States.

A working group of 21 geophysicists and geodesists from four countries representing governmental agencies, industry, and academia developed standards for the revised databases. The revised methodologies used in preparing the principal facts of the gravity observations and reduction of the data to gravity anomalies are based on internationally accepted procedures, protocols, equations, and parameters but in several respects differ significantly from the standard procedures described in current textbooks and used in available databases. These revisions improve the precision and accuracy of the anomalies. On a relative basis the anomaly values of nearby stations are affected only minimally in most regions $[<1 \mathrm{mGal}$ $\left(10^{-3} \mathrm{~cm} / \mathrm{s}^{2}\right.$ or $\left.\left.10^{-5} \mathrm{~m} / \mathrm{s}^{2}\right)\right]$ except in areas of rugged topography where relative changes may exceed $1 \mathrm{mGal}$, but differences of several milligals or more are present in absolute values. In addition to the recommended changes that are in the process of being implemented, several suggestions have been made for future modifications as databases and computational codes are developed and as improved parameters are established.

The revised databases are being made available on an interactive Web portal that will include the principal facts (station observed gravity, coordinates, and height) of each gravity station. Also included are free-air, Bouguer, and isostatic gravity anomalies together with metadata describing related information concerning stations, reduction procedures and constants, and the conversion of gravity observations to anomaly form as available from project/user submissions. The present version of the database for the United States can be accessed on the Web (University of Texas at El Paso). The default values of the North American database will be based on the revised standards for data reduction procedures (Table 1), but the database will have a comprehensive menu of other values, making it useful for those of differing scientific interests and backgrounds. The user will be able to select desired reductions, units, datums, and anomalies and will be able to retrieve information on evaluation of the errors in the data. Accordingly, if desired by the user, principal facts of the gravity stations can be obtained based on conventional procedures.

\section{DATUMS}

The geographic coordinates of gravity observation sites are given in units of degrees of longitude and latitude except for stations of local surveys in which the earth is assumed to be flat and horizontal distances between observations are measured in Cartesian coordinates. Formats of the revised databases provide for geographic positions in decimal degrees up to seven decimal places. To avoid errors arising from varying regional or national horizontal datums, the International Terrestrial Reference Frame (ITRF), in conjunction with the 1980 Geodetic Reference System (GRS80) ellipsoid, is used for the horizontal datum. On a global basis, use of local datums may lead to errors in position of up to $1 \mathrm{~km}$ (Defense Mapping Agency, 1997). In the context of locating gravity stations, the differences between the recent realizations of the 1984 World Geodetic System (WGS84) and the ITRF are negligible.

The WGS84 datum is used in specifying horizontal location in the GPS, and the ITRF is the coordinate system for satellite altimetry-derived gravity data sets over the oceans. The precise WGS84 coordinates agree with the internationally accepted ITRF coordinates within $10 \mathrm{~cm}$. Provision will be made in the Web site menu for converting gravity station coordinates to other horizontal datums, e.g., from the North American Datum (NAD) NAD83 and NAD27 as well as various realizations of the ITRF for the interested user.

The most significant and marked change in the revised standards relates to the choice of the vertical datum. Traditionally, the vertical datum for gravity stations is the geoid or sea level because surface elevations are given with respect to sea level. However, globally there is a difference of $\pm 100 \mathrm{~m}$ in the height between the geoid and the ellipsoid, which is the basis of the theoretical gravity. As a result, there is a longwavelength error in the current procedures that is largely eliminated by using the height relative to the GRS80 ellipsoid rather than to sea level. The revised procedure eliminates the need for the geophysical indirect effect correction ( $\mathrm{Li}$ and Götze, 2001) that is used to minimize the error resulting from 
the use of the geoid as the vertical datum rather than the ellipsoid of the theoretical gravity datum. Additionally, the use of ellipsoid heights avoids problems caused by inconsistencies among local or regional vertical datums. This will be less of a problem in the future as satellite gravity missions pro- vide improved data on the global geoid, and this geoid is incorporated into elevation databases. Also, ellipsoidal heights are advantageous because gravity observation positioning is now commonly obtained by GPS that inherently refers to the height relative to the ellipsoid. It is acknowledged that

Table 1. Comparison between conventional use and recommended revisions of datums and components for computing gravity anomalies.

\begin{tabular}{|c|c|c|}
\hline & Conventional use & Recommended revisions \\
\hline \multicolumn{3}{|l|}{ Datums } \\
\hline $\begin{array}{l}\text { Horizontal datum - datum for locating } \\
\text { geographic position of the gravity } \\
\text { observation site }\end{array}$ & $\begin{array}{l}\text { Nationally selected horizontal control } \\
\text { net }\end{array}$ & $\begin{array}{l}\text { International Terrestrial Reference } \\
\text { Frame (1980 Geodetic Reference } \\
\text { System ellipsoid) }\end{array}$ \\
\hline $\begin{array}{l}\text { Vertical datum - datum for } \\
\text { determining the height of the gravity } \\
\text { observation site }\end{array}$ & $\begin{array}{l}\text { Elevation relative to nationally selected } \\
\text { geoid }\end{array}$ & $\begin{array}{l}\text { International Terrestrial Reference } \\
\text { Frame ellipsoid height (1980 Geodetic } \\
\text { Reference System ellipsoid) }\end{array}$ \\
\hline $\begin{array}{l}\text { Observed gravity - absolute gravity } \\
\text { datum }\end{array}$ & $\begin{array}{l}\text { Referenced to } 1971 \text { International } \\
\text { Gravity Standardization Net } \\
\text { (IGSN71) }\end{array}$ & $\begin{array}{l}\text { Referenced to } 1971 \text { International Gravity } \\
\text { Standardization Net (IGSN71) with } \\
\text { the Honkasalo tidal term removed }\end{array}$ \\
\hline \multicolumn{3}{|l|}{ Anomaly computation } \\
\hline $\begin{array}{l}\text { Theoretical (ellipsoid) gravity - gravity } \\
\text { on the best-fitting ellipsoid of the } \\
\text { earth, including the effect of the } \\
\text { atmosphere }\end{array}$ & $\begin{array}{l}1980 \text { Geodetic Reference System } \\
\text { (GRS80) }\end{array}$ & $\begin{array}{l}\text { Closed form of } 1980 \text { Geodetic Reference } \\
\text { System (GRS80); see equation } 2\end{array}$ \\
\hline $\begin{array}{l}\text { Height correction - gravity effect of } \\
\text { the height of an observation site } \\
\text { relative to the vertical datum }\end{array}$ & $\begin{array}{l}\text { First-order vertical gradient of the } \\
\text { gravity of a homogeneous spherical } \\
\text { earth; } 0.3086 h \text { in } \mathrm{mGal} / \mathrm{m} \text {, where } h \text { is } \\
\text { the elevation of the observation site } \\
\text { in meters above the geoid }\end{array}$ & $\begin{array}{l}\text { Second-order approximation for the } \\
\text { change in theoretical gravity based on } \\
\text { the GRS80 ellipsoid with height } \\
\text { relative to the ellipsoid; see equation } 5\end{array}$ \\
\hline $\begin{array}{l}\text { Bouguer correction - gravity effect of } \\
\text { the mass of the earth between the } \\
\text { vertical datum and the observation } \\
\text { site }\end{array}$ & $\begin{array}{l}\text { Gravity effect (see equation 6) of a } \\
\text { homogeneous slab of density } \sigma \text { of } \\
\text { infinite radius and thickness } h \text { equal } \\
\text { to the elevation of the observation } \\
\text { site in meters above the geoid }\end{array}$ & $\begin{array}{l}\text { Closed-form equation for the gravity } \\
\text { effect of a spherical cap of radius } 166.7 \\
\mathrm{~km} \text { based on a spherical earth with a } \\
\text { radius of } 6371 \mathrm{~km} \text { with height of the } \\
\text { observation site relative to the GRS } 80 \\
\text { ellipsoid; see equation } 7\end{array}$ \\
\hline $\begin{array}{l}\text { Terrain (bathymetry) effect - effect of } \\
\text { topographic (bathymetric) deviation } \\
\text { from the horizontal slab or spherical } \\
\text { cap assumed in calculating the } \\
\text { Bouguer correction }\end{array}$ & $\begin{array}{l}\text { Variable procedures depending on } \\
\text { topographic relief, availability of } \\
\text { terrain data, and required accuracy of } \\
\text { the survey }\end{array}$ & $\begin{array}{l}\text { Three-part terrain effect procedure } \\
\text { based on distance from the station: } \\
\text { (1) estimated topography to } 100 \mathrm{~m} \\
\text { using the attraction of segmented rings; } \\
\text { (2) high-resolution digital height data } \\
\text { from } 100 \text { to } 895 \mathrm{~m} \text { (through Hammer's } \\
\text { Zone F) using segmented rings; } \\
\text { and (3) digital terrain model from } 895 \\
\text { m to } 166.7 \mathrm{~km} \text { using digital terrain } \\
\text { model and effect of vertical prisms } \\
\text { accounting for earth's curvature } \\
\text { beyond } 14 \mathrm{~km}\end{array}$ \\
\hline $\begin{array}{l}\text { Indirect effect correction - gravity } \\
\text { effect from the difference in height } \\
\text { between the ellipsoid on which the } \\
\text { theoretical gravity is given and the } \\
\text { geoid from which the height of } \\
\text { the station is measured }\end{array}$ & $\begin{array}{l}\text { Combined gravity effect of height and } \\
\text { Bouguer corrections because of the } \\
\text { height difference between the } \\
\text { ellipsoid and the geoid; } \\
\text { see equation } 8\end{array}$ & $\begin{array}{l}\text { Unnecessary because the observation site } \\
\text { height is referenced to the ellipsoid on } \\
\text { which the theoretical gravity is given }\end{array}$ \\
\hline $\begin{array}{l}\text { Curvature correction - correction for } \\
\text { the curvature of the earth from the } \\
\text { assumed horizontal slab in the } \\
\text { Bouguer correction }\end{array}$ & $\begin{array}{l}\text { Power series approximation to the } \\
\text { effect of the curvature of the earth to } \\
\text { a distance of } 166.7 \mathrm{~km} \text {; see LaFehr } \\
\text { (1991b, 1998) and Talwani (1998) }\end{array}$ & $\begin{array}{l}\text { Unnecessary because the curvature of } \\
\text { the earth is accounted for in the } \\
\text { closed-form equation for the gravity } \\
\text { effect of a spherical cap; see equation } 7\end{array}$ \\
\hline $\begin{array}{l}\text { Atmospheric correction - correction } \\
\text { for the change in mass of the } \\
\text { atmosphere as a function of height } \\
\text { above the ellip- } \\
\text { soid as a result of the inclusion of the } \\
\text { gravity effect of the atmosphere in } \\
\text { the theoretical gravity on the ellipsoid }\end{array}$ & $\begin{array}{l}\text { Linear approximation from published } \\
\text { tables using an analytical } \\
\text { approximation of the gravity effect of } \\
\text { atmospheric mass or approximated } \\
\text { by equation } 3 \text { up to a height of } 10 \mathrm{~km}\end{array}$ & $\begin{array}{l}\text { Linear approximation from published } \\
\text { tables using an analytical } \\
\text { approximation of the gravity effect of } \\
\text { atmospheric mass or approximated by } \\
\text { equation } 3 \text { up to a height of } 10 \mathrm{~km}\end{array}$ \\
\hline $\begin{array}{l}\text { Isostatic compensation effect }- \text { geo- } \\
\text { logical correction for the subsurface } \\
\text { mass variations which compensate for } \\
\text { topographic variations according to } \\
\text { the theory of isostasy that the earth at } \\
\text { some depth is in hydrostatic } \\
\text { equilibrium }\end{array}$ & $\begin{array}{l}\text { Variable procedures and assumptions } \\
\text { regarding the method of } \\
\text { compensation within the earth }\end{array}$ & $\begin{array}{l}\text { Airy-Heiskanen model based on the } \\
\text { assumption of local isostatic } \\
\text { compensation produced by variations } \\
\text { in the crust-mantle boundary with a } \\
\text { density contrast of } 300 \mathrm{~kg} / \mathrm{m}^{3} \text { and a } \\
\text { depth of } 30 \mathrm{~km} \text { for a surface height of } \\
\text { sea level }\end{array}$ \\
\hline
\end{tabular}


ellipsoidal heights generally will not be zero at the ocean shoreline and in ocean areas because of the vertical separation between the geoid (sea level) and the ellipsoid. As a result, free-air and simple Bouguer gravity anomalies will not be equivalent at the shoreline as is the case when sea level is used as the vertical datum.

Users of the Web site menu-driven database may select the option of using elevation relative to the local geoid as in current databases rather than the ellipsoid height of the revised standards. Additionally, the Web site menu of the databases will provide for conversion of elevations of other vertical datums such as the National Geodetic Vertical Datum (NGVD) NGVD29, the Canadian Geodetic Vertical Datum (CGVD) CGVD28, and the North American Vertical Datum (NAVD) NAVD88 to ITRF-based heights. Elevations referenced to the geoid can be converted to ellipsoid heights by, for example, GEOID03 in the United States. We anticipate that the database will incorporate provisions for updated geoid models.

Gravity values are referenced to the 1971 International Gravity Standardization Net (IGSN71) (Morelli et al., 1974). However, published IGSN71 values include a correction the Honkasalo term (Honkasalo, 1964) — which removes the average part of the tidal force. This correction has been deemed inappropriate (Heikkinen, 1979) because of resulting errors in calculation of the geoid from gravity values corrected with the Honkasalo term. Thus, following a recommendation of the International Association of Geodesy (Uotila, 1980), the Honkasalo term $\Delta g_{H}$ is removed from IGSN71 values by adding the latitudinal-dependent correction in milligals as given in equation 1 :

$$
\Delta g_{H}=0.0371\left(1-3 \sin ^{2} \varphi\right),
$$

where $\varphi$ is the latitude (south or north) of the station. The correction for removal of the Honkasalo term varies from +0.04 $\mathrm{mGal}$ at the equator to $-0.02 \mathrm{mGal}$ at $45^{\circ}$ to $-0.07 \mathrm{mGal}$ at the poles.

Widely accepted procedures (e.g., Torge, 1989; Telford et al., 1990) are used to convert raw gravity measurements to observed gravity. These may include tidal corrections, gravimeter drift, local atmospheric effects, calibration of gravimeters, and ties to gravity base stations. We note that there is a need for internationally accepted standards for these gravity observation and instrumentation procedures.

\section{REDUCTION OF OBSERVED GRAVITY DATA TO ANOMALIES}

Raw gravity data are affected by a wide variety of sources of varying amplitudes, periods, and wavelengths that generally mask gravity variations of geologic or geophysical interest. As a result, field observations are processed to minimize these extraneous effects. This conversion procedure is commonly referred to as correction or reduction of the gravity data. Correction does not imply that errors are present in the data, and reduction does not suggest that the data are reduced to a common vertical datum; but both terms refer to the conversion of raw gravity observations to anomaly form. A gravity anomaly is the difference between the observed gravity and the modeled or predicted value of gravity at the station. The observed value is a conversion of the raw gravimeter measurement to the absolute gravity at the station, corrected for temporal variations using ties to stations of known gravity; the modeled or theoretical value of gravity at a station takes into account planetary and topographical gravitational effects. Further interpretive models attempt to account for known or prescribed geological effects that cause variations in the gravity field.

\section{Ellipsoid theoretical gravity}

The theoretical or normal gravity accounting for the mass, shape, and rotation of the earth is the predicted gravitational acceleration on the best-fitting terrestrial ellipsoidal surface. The latest ellipsoid recommended by the International Union of Geodesy and Geophysics is the 1980 Geodetic Reference System (GRS80) (Moritz, 1980). The Somigliana closed-form formula (Somigliana, 1930) for the theoretical gravity $g_{T}$ on this ellipsoid at latitude (south or north) $\varphi$, is

$$
g_{T}=\frac{g_{e}\left(1+k \sin ^{2} \varphi\right)}{\left(1-e^{2} \sin ^{2} \varphi\right)^{1 / 2}},
$$

where the GRS80 reference ellipsoid has the value $g_{e}$ of $978032.67715 \mathrm{mGal}$, where $g_{e}$ is normal gravity at the equator; $k$ of 0.001931851353 , where $k$ is a derived constant; and $e^{2}$ of 0.0066943800229 , where $e$ is the first numerical eccentricity.

Updated ellipsoids have been developed since 1980, but they have a negligible effect (measured in thousandths of a milligal) on the theoretical gravity. Until a new ellipsoid is internationally accepted, the GRS80 will be used. Theoretical values based on previous internationally accepted reference systems will be accessible to users in the menu of the Web site database.

\section{Atmospheric effect}

The mass of the earth's atmosphere is included with the mass of the solid earth in determining the ellipsoidal theoretical gravity given by the 1980 International Gravity Formula (Moritz, 1980). However, the mass of the atmosphere above a gravity station does not affect the station's measured gravity, assuming that the atmosphere consists of homogeneous spherical shells. The gravitational potential attributable to a homogeneous shell at any point within that shell is constant; thus, the gravity from an overlying shell is zero. The gravity effect of the atmospheric mass is approximated with a model atmosphere using an analytical expression described by Ecker and Mittermayer (1969) and reprinted in Moritz (1980) or calculated to the nearest one-hundredth of a milligal up to a height of $10 \mathrm{~km}$ with the equation (Wenzel, 1985)

$$
\delta g_{a t m}=0.874-9.9 \times 10^{-5} h+3.56 \times 10^{-9} h^{2},
$$

where the gravity effect is given in milligals and $h$ is the height of the station in meters. This correction, which is needed in accurate surveys that cover a broad range of heights, is subtracted from the ellipsoidal theoretical gravity at a station. Consideration of the atmospheric effect correction increases a gravity anomaly by approximately $0.86 \mathrm{mGal}$ at a height of $100 \mathrm{~m}$ and by roughly $0.77 \mathrm{mGal}$ at $1000 \mathrm{~m}$. 


\section{Height correction}

Historically, the height correction is called the free-air correction and is based on the elevation (or orthometric height) above the geoid (sea level) rather than the height above the ellipsoid. As described above, the revised standards use the ellipsoid as the vertical datum rather than sea level (Table 1). Conventionally, the first-order approximation formula of $\delta g_{h}$ in milligal, or $0.3086 h$, is used for this correction. To improve its accuracy, the second-order approximation formula (Heiskanen and Moritz, 1969) is used for correcting the theoretical gravity for a height $h$ (meters) relative to the ellipsoid:

$\delta g_{h}=-\frac{2 g_{e}}{a}\left[1+f+m+\left(-3 f+\frac{5}{2} m\right) \sin ^{2} \varphi\right] h+\frac{3 g_{e} h^{2}}{a^{2}}$.

The GRS80 ellipsoid has the following parameter values: $a$, the semimajor axis, is $6378137 \mathrm{~m}$; $b$, the semiminor axis, is $6356752.3141 \mathrm{~m}$; $f$, flattening, is 0.003352810681 ; $g_{e}$ is $9.7803267715 \mathrm{~m} / \mathrm{s}^{2}$; and $m$, which is $\omega^{2} a^{2} b^{2} / G M$, is 0.00344978600308 , where $\omega$ is angular velocity $(7292115 \times$ $10^{-11}$ radians/s) and $G M$ is a geocentric gravitational constant $\left(3986005 \times 10^{8} \mathrm{~m}^{3} / \mathrm{s}^{2}\right)$. For the GRS80 ellipsoid the secondorder formula is

$\delta g_{h}=-\left(0.3087691-0.0004398 \sin ^{2} \varphi\right) h+7.2125 \times 10^{-8} h^{2}$,

where the ellipsoid height $h$ is in meters and the gravity effect is in milligals. Depending on the latitude, the difference between the first-order and second-order correction may be as large as several milligals at heights of several thousand meters (Li and Gotze, 2001).

\section{Bouguer correction}

The Bouguer correction accounts for the gravitational attraction of the layer of the earth between the vertical datum, i.e., the ellipsoid, and the station. This correction, $\delta g_{B C}$ in milligals, traditionally is calculated assuming the earth between the vertical datum and the station can be represented by an infinite horizontal slab with the equation

$$
\delta g_{B C}=2 \pi G \sigma h=4.193 \times 10^{-5} \sigma h,
$$

where $G$, the gravitational constant, is $6.673 \pm 0.001 \times 10^{-11}$ $\mathrm{m}^{3} / \mathrm{kg} / \mathrm{s}^{2}$ (Mohr and Taylor, 2001), $\sigma$ is the density of the horizontal slab in kilograms per cubic meter, and $h$ is the height of the station in meters relative to the ellipsoid in the revised procedure or relative to sea level in the conventional procedure.

In the revised procedure, to account for the effect of the curvature of the earth, the horizontal slab equation is replaced by the closed-form formula for a spherical cap of radius 166.7 $\mathrm{km}$ (LaFehr, 1991b), that is,

$$
\delta g_{S C}=2 \pi G \sigma(\mu h-\lambda R),
$$

where $\mu$ and $\lambda$ are dimensionless coefficients defined by LaFehr, $R$ is the radius of the earth $\left(R_{o}+h\right)$ at the station where $R_{o}$ is the mean radius of the earth, $h$ is the height above the ellipsoid, and $\sigma$ is the density of the material making up the spherical cap. The gravitational effect of the spherical cap is smaller than the horizontal slab formulation because of the conventional truncation at $166.7 \mathrm{~km}$ and is larger because of the greater gravitational attraction resulting from the downward curvature of the slab as compared to the horizontal slab. The latter dominates to an elevation of roughly 4150 $\mathrm{m}$, where the effect of the truncation and the curvature of the slab are equal. Their combined effect attains a positive value of roughly $1.5 \mathrm{mGal}$ at approximately $2100 \mathrm{~m}$ and continues to decrease at elevations of greater than $4150 \mathrm{~m}$, reaching a value of roughly $-1.5 \mathrm{mGal}$ at $5000 \mathrm{~m}$.

The density $\sigma$ used in calculating the Bouguer correction depends on the material making up the spherical cap. In local surveys, this value is determined by the density of the geological materials between the survey and the local vertical datum. However, in regional and continental databases, a mean density is used for the spherical cap, typically $2670 \mathrm{~kg} / \mathrm{m}^{3}$ for the solid earth (Chapin, 1996b; Hinze, 2003), $1027 \mathrm{~kg} / \mathrm{m}^{3}$ for sea water, $1000 \mathrm{~kg} / \mathrm{m}^{3}$ for fresh water, and $917 \mathrm{~kg} / \mathrm{m}^{3}$ for ice. In the future, as more definitive information is obtained on the density of solid-earth materials subjacent to gravity stations, it may be desirable to use a density appropriate for the station location rather than the $2670 \mathrm{~kg} / \mathrm{m}^{3}$ average value (Hackney and Featherstone, 2003; Hinze, 2003). Use of different densities from station to station may not be desirable when using station anomalies for modeling because variable densities can be applied directly in the modeling. However, variable densities are advantageous in eliminating errors in anomaly values where they are used directly in map form for interpretation, as with regional anomalies derived from the U.S. and North American gravity databases. This is especially true where densities vary from the average value used in the reduction of the data and where rugged topography occurs over the map area - the case over significant portions of North America.

\section{Indirect effect}

The geophysical indirect effect, which is applicable when calculating all anomalies, is the gravitational effect produced by using different vertical datums to establish the height of the station and to specify the theoretical gravity. The adjective "geophysical" differentiates this effect from the indirect effect of geodesy, which is the correction applied to the compensated geoid (cogeoid) that is derived from gravity anomalies downward-continued to the geoid (Hackney and Featherstone, 2003). Conventionally, in gravity reductions the height datum is the geoid and the gravity datum is the internationally accepted ellipsoid of the earth. The difference between ellipsoid (geometric) height and elevation (orthometric height) relative to the geoid attains maximum values globally of about $\pm 100 \mathrm{~m}$ and has a range of roughly $80 \mathrm{~m}$ over North America and adjacent oceans. The indirect effect combines the effect of the difference in height with the gravity effect of the mass between the two datums as given in the Bouguer correction. Assuming a horizontal layer of thickness equal to this difference for land stations, the indirect effect $\delta g_{I E}$ in milligals is

$$
\delta g_{I E}=(0.3086-2 \pi G \sigma) N=0.1976 N,
$$

where $N$ is the geoid height in meters and assuming a density $\sigma$ of $2670 \mathrm{~kg} / \mathrm{m}^{3}$ for the layer. Thus, the maximum indirect effect is on the order of $20 \mathrm{mGal}$. A similar correction of $0.2655 \mathrm{~N}$ 
$\mathrm{mGal} / \mathrm{m}$ is needed for marine gravity observations (Chapman and Bodine, 1979).

The indirect effect, which has the same sign as the geoid height, varies slowly with distance because of the low horizontal gradient of the geoid. The amplitude changes of the geoid height for distances shorter than $10 \mathrm{~km}$ are usually smaller than $10 \mathrm{~cm}$ and are considerably smaller than $1 \mathrm{~m}$ for wavelengths less than $100 \mathrm{~km}$. As a result, this correction is neglected in local surveys because of its minimal effect, or it is removed as part of the regional anomaly in the regional/residual separation process. However, the effect can interfere with interpretation of long-wavelength anomalies that are of increasing interest in continental-scale mapping.

The use of the GRS80 ellipsoid in the ITRF reference frame as the datum minimizes the difference accounted for in the indirect effect. Thus, this correction is not included in the revised procedures for the reduction of gravity data.

\section{Terrain and bathymetry correction}

The gravity effect of departures of topography from the assumed horizontal slab or spherical cap used in making the Bouguer correction is referred to as the terrain correction. Terrain corrections may include bathymetry of bodies of water. The application of terrain corrections to gravity data minimizes rugged topographic effects that may cause errors in the gravity anomalies of tens of milligals. Efficient and effective use of these corrections requires comprehensive digital elevation models and computational power that is only now becoming generally available.

The U.S. and North American gravity database processing methods use a three-part procedure for computing terrain corrections. The first part, which is the responsibility of the data collector, uses near-station topographic information collected in the field either by GPS, optical, or electronic instrumentation to a distance of about $100 \mathrm{~m}$ from the station to calculate terrain effects using the gravitational attraction of a pattern of segmented rings centered on the station (Hammer, 1939). The second portion, also based on segmented rings, uses local high-resolution height data (e.g., 10- and 30-m-grid data) to calculate terrain effects to a distance of $895 \mathrm{~m}$, a distance that includes Hammer's Zone F. The final part involves digital terrain model data to compute the terrain effects (e.g., Godson and Plouff, 1988) from $895 \mathrm{~m}$ to $166.7 \mathrm{~km}$ based on $15-\mathrm{s}$ and 1- and 3-min topographic grids and accounting for the earth's curvature beyond $14 \mathrm{~km}$. These individual parts of the correction will be available in the principal facts. This will allow users to replace one or more parts of the correction with revisions obtained with more accurate and dense terrain (and bathymetry) data or to use alternative procedures to calculate the correction.

The use of elevations (orthometric heights) for the heights of gravity stations and in the heights of digital terrain models rather than ellipsoidal heights results in errors from geoidal variations over the area of the terrain correction evaluation. The resulting errors are negligible for most geophysical purposes because of the low gradients of the geoid; but for consistency in procedures and to eliminate these errors in the future, digital elevation models should be converted to digital height models for terrain correction procedures. Furthermore, we anticipate that long-term modifications to these procedures will extend the terrain and bathymetry corrections to $500 \mathrm{~km}$ and beyond using 2- and 5-min terrain and bathymetry grids and an elliptical earth. Eventually, a global correction will be available for terrain corrections, including densities that can be modified for surface geologic variations.

\section{Isostatic compensation effect}

The isostatic compensation correction is the gravity effect derived from a geologic model based on the theory of isostasy that regional topographic variations are compensated by density changes of the lithosphere such that at some depth, the earth is in hydrostatic equilibrium. As a result of isostasy, a strong inverse correlation exists between regional terrain and Bouguer gravity anomalies. To minimize the effect of these regional subsurface variations on anomalies, their gravitational response is modeled with the simplifying assumption that crustal thickness varies directly with local topography. This isostatic compensation correction is calculated in a manner similar to the terrain effect using the Airy-Heiskanen model (Heiskanen and Vening Meinesz, 1958) with a modified version of the procedure of Jachens and Roberts (1981) that assumes local isostatic compensation. The correction for varying depth to a hypothetical crust-mantle boundary caused by differential topographic or bathymetric loads above or below the ellipsoid assumes a density variation of $300 \mathrm{~kg} / \mathrm{m}^{3}$ and a crustal thickness of $30 \mathrm{~km}$ for sea-level surface elevation based on average global crust/upper mantle density contrast and crustal thickness (Christensen and Mooney, 1995). Topography is modeled assuming a continental crustal density of $2670 \mathrm{~kg} / \mathrm{m}^{3}$ using three-minute elements of topography to $166.7 \mathrm{~km}$ plus interpolated values from $166.7 \mathrm{~km}$ to $180^{\circ}$ from tables in Karki et al. (1961).

In the future, it will be desirable to perform isostatic correction calculations using a method in the space domain consistent with the procedures for calculating the terrain gravity effects using global digital height and bathymetry models and taking into account the ellipticity of the earth. These modifications will have a negligible effect for most geophysical purposes but will improve consistency and minimize errors. Additionally, efficiency will be improved by using an analytical form for determining isostatic effects from $166.7 \mathrm{~km}$ to $180^{\circ}$ rather than interpolated values from Karki et al. (1961).

\section{GRAVITY ANOMALIES}

Gravity anomalies calculated by the modified reduction procedures detailed above will be available in the revised databases. Anomalies are the difference between the observed gravity, typically its absolute value corrected for temporal variations, and the modeled or theoretical gravity at the site of the observation. Different types of anomalies reflect variations in the components used in defining the modeled gravity at the station. The models change, depending upon the use of the anomaly in geophysical studies.

Free-air gravity anomalies have their greatest use in geodesy and are frequently used in modeling and map interpretation in marine areas. Calculation of this anomaly involves obtaining the difference between the observed gravity and the modeled gravity at the station, taking into account the theoretical gravity on the GRS80 ellipsoid using a 3D station location based on the ITRF and the atmospheric correction. 
The Bouguer gravity anomaly is determined from the difference in the observed gravity and the modeled gravity using the free-air model plus the Bouguer and terrain model effects. The Bouguer anomaly is used primarily in the modeling and map interpretation of land gravity anomalies. Isostatic gravity anomalies are used in interpreting regional gravity anomalies, especially in map form, although care must be taken to consider the potential problems in the calculation of this anomaly derived from the assumption of isostatic compensation associated with local topographic variations (Simpson et al., 1986; Chapin, 1996b). This anomaly is calculated by adding the effect of the isostatic compensation effect to the Bouguer gravity anomaly.

A potential source of confusion regarding the term anomaly stems from a difference in nomenclature between the geodesy and geophysical communities (Fairhead et al., 2003; Hackney and Featherstone, 2003). Geodesists use gravity anomalies to determine the figure of the earth, while geophysicists use anomalies to interpret variations in mass that reflects subsurface geology. Traditionally, in geodesy the difference between the observed and modeled gravity at a station is referred to as an anomaly when the vertical datum is the geoid, while it is termed a disturbance when the vertical datum is the ellipsoid. In the procedures specified for the revised databases, the vertical datum is the ellipsoid. Thus, to be consistent with geodetic nomenclature, the term disturbance rather than anomaly could be considered for what is now termed anomaly in geophysical gravity studies. This would serve the purpose of identifying the difference in observed and modeled gravity using the ellipsoid as the vertical datum from the anomaly based on the sea-level datum. However, the difference in the ellipsoidand sea-level-based anomalies is really rather minor - generally less than $10 \mathrm{mGal}$ - and, as described above, the difference is in the long-wavelength, regional components of the gravity field. Thus, the difference in the anomalies does not affect most gravity exploration interpretation. Furthermore, the term anomaly is thoroughly ingrained in the language and literature of geophysicists. As a result, the use of disturbance rather than anomaly is unlikely to be accepted by the community and will lead to confusion in the use of the gravity method, especially among nonspecialists. The geophysical community is largely unaware of the term disturbance as used by geodesists, which will add further confusion if the term is used.

The solution to this dilemma is not to revert to the sealevel vertical datum because of the advantages which accrue from the use of the ellipsoidal datum. The revised databases have improved accuracy, particularly in long-wavelength gravity anomalies, as a result of incorporating the geophysical indirect effect into the revised standards and using the same vertical datum for all regions. Also, use of the ellipsoid is consistent with the heights inherently obtained by GPS, which is becoming much more important in determining the heights of gravity stations. Existing stations that are referenced to sea level are readily converted to ellipsoidal heights with existing codes and databases.

As a result of the advantages of implementing the revised reduction procedures we can anticipate that not only will the North American gravity databases use them, but that they will also increasingly become the norm in gravity reduction. Therefore, the anomalies calculated using the two different vertical datums will coexist. To minimize the appar- ent inconsistency between the results of these two gravity reduction procedures, we propose that the adjective ellipsoidal precede the anomaly term, e.g., ellipsoidal Bouguer gravity anomaly, to specify the vertical datum of the reduction procedure and to alert the user to the use of the modified procedure. This is an equivalent approach to the terms simple and complete Bouguer gravity anomaly, indicating whether the gravity anomaly includes a terrain correction. In this sense the adjective is used in an informal manner. It is likely that the term ellipsoidal will fall into disuse with widespread adoption of the revised procedures, and it will be needed to a decreasing degree as the revised reduction procedure becomes standard in gravity analysis and existing data sets are converted to the revised procedures.

\section{SUMMARY}

Modified reduction procedures are incorporated into the standards of the North American and associated gravity databases, thereby improving the accuracy and geophysical utility of gravity anomalies. These revisions use a single horizontal datum for locating gravity stations and the internationally accepted terrestrial ellipsoid as the vertical datum for stations to avoid problems originating in local or regional datums. Changes in the reduction procedures minimize errors attributable to terrain, earth curvature, second-order vertical gradients in gravity, atmospheric mass effects, and differences in the normal gravity and station height datums. Their consistent use improves the accuracy and precision of gravity anomalies, especially in their long-wavelength components. The most significant difference in the revised procedures is the use of the ellipsoid as the vertical datum rather than conventionally used sea level. This leads to minor, but measurable, differences in the absolute values of anomalies, which may cause confusion with previous gravity data. Thus, it is advisable to informally recognize that an anomaly calculated using the revised procedures is termed an ellipsoidal gravity anomaly. The revised procedure is recommended for future gravity reductions and should be used to recalculate anomalies in existing data sets.

\section{ACKNOWLEDGMENTS}

We are pleased to acknowledge the useful reviews of four referees and an associate editor, which have improved our manuscript.

\section{REFERENCES}

Chapin, D. A., 1996a, The theory of the Bouguer gravity anomaly: A tutorial: The Leading Edge, 15, 361-363.

, 1996b, A deterministic approach toward isostatic gravity residuals - A case study from South America: Geophysics, 61, 1022-1033.

Chapman, M. E., and J. H. Bodine, 1979, Considerations of the indirect effect in marine gravity modeling: Journal of Geophysical Research, 84, 3889-3892.

Christensen, N. I., and W. D. Mooney, 1995, Seismic velocity structure and composition of the continental crust: A global view: Journal of Geophysical Research, 100, 9761-9788.

Committee for the Gravity Anomaly Map of North America, 1987, Gravity anomaly map of North America: Geological Society of America Continental-Scale Map 002, scale 1:5 000 000, 5 sheets.

Defense Mapping Agency, 1997, Department of Defense World Geodetic System 1984: Its definition and relationships with local geodetic systems: Technical Report 8350.2. 
Ecker, E., and E. Mittermayer, 1969, Gravity corrections for the influence of the atmosphere: Bulletin of Theoretical and Applied Geophysics, 11, 70-80.

Fairhead, J. D., C. M. Green, and D. Blitzkow, 2003, The use of GPS in gravity surveys: The Leading Edge, 22, 954-959.

Godson, R. H., 1985, Preparation of a digital grid of gravity anomaly values of the conterminous United States, in W. J. Hinze, ed., The utility of regional gravity and anomaly maps: SEG, 38-45.

Godson, R. H., and D. Plouff, 1988, BOUGUER Version 1.0, A microcomputer gravity-terrain-correction program: U.S. Geological Survey Open-File Report 88-644.

Hackney, R. I., and W. E. Featherstone, 2003, Geodetic versus geophysical perspectives of the "gravity anomaly": Geophysical Journal International, 154, 35-43.

Hammer, S., 1939, Terrain corrections for gravimeter stations: Geophysics, 4, 184-194.

Heikkinen, M., 1979, On the Honkasalo term in tidal corrections to gravimetric observations: Journal of Geodesy, 53, 239-245.

Heiskanen, W. A., and F. A. Vening Meinesz, 1958, The earth and its gravity field: McGraw-Hill Book Company.

Heiskanen, W. A., and H. Moritz, 1969, Physical geodesy: W. H. Freeman Co.

Hinze, W. J., 2003, Bouguer reduction density - Why 2.67?: Geophysics, 68, 1559-1560.

Honkasalo, T., 1964, On the tidal gravity correction: Bulletin of Theoretical and Applied Geophysics, 6, 34-36.

Hubbert, M. K., and F. A. Melton, 1928, Gravity anomalies and petroleum exploration by the gravitational pendulum: AAPG Bulletin, 12, 889-899.

Jachens, R. C., and C. Roberts, 1981, Documentation of program, ISOCOMP, for computing isostatic residual gravity: U.S. Geological Survey Open-File Report 81-0574.

Karki, P., L. Kivioja, and W. A. Heiskanen, 1961, Topographic isostatic reduction maps for the world to the Hayford zones 18-1, AiryHeiskanen system, $T=30 \mathrm{~km}$ : Isostatic Institute of the International Association of Geodesy, 35.

LaFehr, T. R., 1991a, Standardization in gravity reduction: Geophysics, 56, 1170-1178.

LaFehr, T. R., 1991b, An exact solution for the gravity curvature (Bullard B) correction: Geophysics, 56, 1179-1184.

LaFehr, T. R., 1998, On Talwani's "Errors in the total Bouguer reduction”: Geophysics, 63, 1131-1136.
Li, X., and H.-J. Götze, 2001, Tutorial: Ellipsoid, geoid, gravity, geodesy, and geophysics: Geophysics, 66, 1660-1668. (with the Erratum in 67,997 )

Mohr, P. J., and B. N. Taylor, 2001, The fundamental physical constant: Physics Today, 54, 6-16.

Morelli, C., ed., 1974, The International Gravity Standardization Net 1971: International Association of Geodesy, Special Publication 4.

Moritz, H., 1980, Geodetic Reference System 1980: Journal of Geodesy, 54, 395-405.

O'Hara, N. W., and P. L. Lyons, 1985, Preparation and overview of the gravity anomaly map of the United State, in W. J. Hinze, ed., The utility of regional gravity and anomaly maps: SEG, 33-37.

Olivier, R., and W. J. Hinze, 1986, Potential fields in rugged topography: The Leading Edge, 9, 5 .

Simpson, R. W., R. C. Jachens, R. J. Blakely, and R. W. Saltus, 1986, A new isostatic residual gravity map of the conterminous United States with a discussion on the significance of isostatic residual anomalies: Journal of Geophysical Research, 91, 8348-8372.

Society of Exploration Geophysicists, 1982, Gravity anomaly map of the United States (exclusive of Alaska and Hawaii): SEG, scale 1: 2500000,2 sheets.

Somigliana, C., 1930, Geofisica - Sul campo gravitazionale esterno del geoide ellissoidico: Atti della Accademia nazionale dei Lincei. Rendiconti. Classe di scienze fisiche, matematiche e naturali, 6, 237243.

Talwani, M., 1998, Errors in the total Bouguer reduction: Geophysics, 63, 1125-1130.

Telford, W. M., L. P. Geldart, and R. E. Sheriff, 1990, Applied geophysics: Cambridge University Press.

Torge, W., 1989, Gravimetry: Walter de Gruyter Publishing Co.

University of Texas at El Paso, Pan-American Center for Earth and Environmental Studies, Posted, 29 January 2004. http://paces. geo.utep.edu.

Uotila, U. A., 1980, Note to users of International Gravity Standarization Net 1971: Journal of Geodesy, 54, 407-408.

Wenzel, H., 1985, Hochauflosende Kugelfunktionsmodelle fur des Gravitationspotential der Erde [1]: Wissenschaftliche arbeiten der Fachrichtung Vermessungswesen der Universitat Hannover, 137.

Woollard, G. P., and H. R. Joesting, 1964, Bouguer anomaly map of the United States: U.S. Geological Survey Special Map, scale 1: $2500.000,2$ sheets. 